degenerate. Relief of pain is more likely than restoration of movement. When it is the cause of the symptoms the evacuation of a localised calcified deposit of toothpaste-like material can be very rewarding. Complete acromionectomy prejudices the power of the deltoid muscle and partial excision is apt to fail to relieve the trouble. The whole glenohumeral joint can be lowered away from the acromion by glenoid osteotomy. ${ }^{6}$ In the past little attention has been paid to the acromioclavicular joint in the painful arc syndrome. It may be that, as is now suggested, ${ }^{4}$ excision of the outer centimetre of the clavicle should be more often considered when a resistant example of the syndrome is accompanied by degenerative changes in the acromioclavicular joint.

${ }^{1}$ Bulgen, D Y, Hazleman, B L, and Voak, D, Lancet, 1976, 1, 1042.

2 Macnab, I, Annals of the Royal College of Surgeons of England, 1973, 53, 271

${ }^{3}$ Blockey, N J, Wright, J K, and Kellgren, J H, British Medical fournal, $1954,1,1455$.

${ }^{4}$ Kessel, L, and Watson, M, fournal of Bone and foint Surgery, 1977, 59B, 166.

5 Neer, C S, fournal of Bone and foint Surgery, 1972, 54A, 41.

${ }^{6}$ Richards, D J, fournal of Bone and foint Surgery, 1969, 51 B, 179.

\section{Drinking behaviours}

\begin{abstract}
"In the tragic conflict between what he has been taught to desire and what he is allowed to get, a man has found in alcohol, as he has found in certain other drugs, a sinister but effective peacemaker, a means of securing for however short a time some way out of the prisonhouse of reality back to the Golden Age."
\end{abstract}

\section{WILFRED TROTTER, 1908}

In the tragedy of addiction the spotlight for too long has played on those who (in Britain at any rate) deserve to be billed only as bit-part actors-the junkies, the pot-smokers, and the pep-pill swillers. There has been a recent, welcome shift in the focus on to the near-forgotten victims of the real villain of the piece, the demon alcohol.

Alcoholism, or the "alcohol dependence syndrome," the term preferred in a recent WHO publication, ${ }^{1}$ is undoubtedly a main cause of both obvious and hidden physical and mental illness, of family disruption and social embarrassment, and a burden on the health services. What is new and deplorable is the rising scale of alcohol abuse among the young of both sexes and among women in general. In Britain alone there are estimated to be 300000 alcoholics. Their contribution to crime is enormous: there are as many as 75000 convictions for public drunkenness every year, and of those otherwise convicted between $40 \%$ and $60 \%$, have an alcohol problem. Alcohol disinhibits and releases aggression that can be directed outwards, leading to assaults on others, or directed inwards, resulting in suicidal attempts. Glatt ${ }^{2}$ found that at Warlingham Park Hospital nearly half the men alcoholics and more than one-third of the women conceded that when in drink they had behaved aggressively or had endangered themselves or others.

The crisis point for those who abuse alcohol is the loss of freedom of choice: the point, that is, when there is no option but to drink and to continue drinking, whether it be continuously, intermittently, or episodically. According to van Dijk ${ }^{3}$ alcoholism is a self-perpetuating disease and to explain his convincing thesis he has constructed a model of four interrelated vicious circles: the pharmacological, the cerebral, the psychological, and the social. Each circle reinforces the others, and the longer they continue to do so the more difficult does treatment become.

But in spite of the widespread prevalence of the alcohol dependence syndrome there is a correspondingly widespread conspiracy to conceal the victim-a conspiracy entered into by the alcoholic and his family for fear, no doubt, of public opprobrium. These attempts at concealment are themselves tragic because-contrary to general belief-the alcoholic can be helped substantially, and the sooner he seeks help the better. The average general practitioner is thought to be aware of only two or so of the 15 alcoholics in his practice. ${ }^{2}$ If he is to be, as he should be, the spearhead of the attack on alcoholism it is imperative that he should be constantly on the alert for its symptoms, often subtle and masked.

In this context a recent WHO publication ${ }^{1}$ is of particular importance. It describes some drinking behaviours (which in many ways complement van Dijk's vicious circles). Firstly, somatopathic drinking results in hangover or damage to tissues, such as gastritis, hepatitis, or myopathy. Second is thymogenic drinking, in which alcohol is essential in order to cope with the emotional problems of living. The third behaviour is dyssocial drinking leading to breaches of the criminal law, such as drunken driving; or to disruption of family or social relations; or to economic and occupational impairment. Lastly, there may be combinations of two behaviours, and any combination is strongly indicative of alcoholism, or at least of its prodromal stage. A combination of all three leaves no doubt that the worst has happened: a confident diagnosis of alcohol dependence syndrome may be made.

No one who drinks is above suspicion: the bell may toll for him. ${ }^{1}$ Alcohol-Related Disabilities, eds G Edwards et al. Geneva, World Health
Organisation, (offset publ No 32), 1977 .
${ }^{2}$ Glatt, M, The Alcoholic and the Help He Needs, 2nd edn. London, Priory
Press, 1972.

${ }^{3}$ van Dijk, W K, Medicine (London), 1975, No 13 pt 1, p 598.

\section{Relapse in leprosy}

Relapse in leprosy is no new thing. In the pre-sulphone era relapse after treatment with chaulmoogra oil or a derivative of hydnocarpic acid was the rule rather than the exception in cases of multibacillary leprosy. Hopes of permanent arrest of the disease were raised by the glowing reports when the sulphones ${ }^{1}$ were introduced in the early 1940s. Tuberculoid leprosy responded well, and relapse was uncommon when treatment was taken regularly and for long enough. In those days relapse was also rare in patients with lepromatous leprosy, but in patients suffering from intermediate types (borderline or dimorphous) the fairly rapid disappearance of skin lesions deluded clinicians into equating apparent clinical quiescence with cessation of mycobacterial multiplication: hence there was a high relapse rate in such cases in some series. $^{2}$

Today in well-supervised leprosy control programmes reactivation of the disease after insufficient treatment is less a cause for concern than is relapse that occurs despite adequate intake and absorption of an effective mycobacteriostatic drug, usually dapsone. ${ }^{3}$ The main reason for this increasingly disturbing trend is the emergence of dapsone-resistant leprosy 